\title{
Amelioration of heat stress-induced hepatic injury in wistar rats by zinc- enriched probiotics: Role of hepatic antioxidant status and serum enzymes activity
}

Rahmani Mohammad Malyar,1,2, Jamal Tanha ${ }^{3}$, Zia Ziauddin ${ }^{4}$, Kamal Said Ismail ${ }^{5}$, Mumtaz Ibrahimi ${ }^{5}$, Aziz Ur Rahman Khalid ${ }^{5}$, Bawari Hanifullah $^{6}$, Sayed Attaul Haq Banuree ${ }^{2}$ and Waseem Ali Vistro ${ }^{7 *}$

1. Institute of Nutritional and Metabolic Disorders in Domestic Animals and Fowl, College of Veterinary Medicine, Nanjing Agricultural University. Nanjing 210095, China

2. Veterinary Science Faculty, Nangarhar University, Nangarhar Province, Afghanistan

3. Animal Science department, Agriculture Faculty, Laghman University, Laghman Province, Afghanistan

4. Animal Science department, Agriculture Faculty, Said Jamaluddin Afghani University, Kunar Province, Afghanistan

5. Veterinary Science Faculty, Shaikh Zayed University, Khost Province, Afghanistan

6. Veterinary Science Faculty, Helmand Institute of Higher Education, Helmand Province, Afghanistan

7. Faculty of Animal Husbandry and Veterinary Sciences, Sindh Agriculture University Tandojam, Pakistan

*Corresponding author's email: drwaseemvistro@gmail.com

Citation

Rahmani Mohammad Malyar, Jamal Tanha, Zia Ziauddin, Kamal Said Ismail, Mumtaz Ibrahimi, Aziz Ur Rahman Khalid, Bawari Hanifullah, Sayed Attaul Haq Banuree and Waseem Ali Vistro. Amelioration of heat stress-induced hepatic injury in wistar rats by zinc-enriched probiotics: Role of hepatic antioxidant status and serum enzymes activity. Pure and Applied Biology. Vol. 10, Issue 4, pp1494-1503. http://dx.doi.org/10.19045/bspab.2021.100155

\begin{tabular}{llll}
\hline \hline Received: 03/02/2021 & Revised: 23/04/2021 & Accepted: 27/04/2021 & Online First: 30/04/2021 \\
\hline \hline
\end{tabular}

\section{Abstract}

Zinc-Enriched probiotics improve liver condition of Wistar rats reared under heat stress. For this purpose, four groups of ten-week-old Wistar rats were as follow: Control (Con); heat stress (HS); probiotics plus heat stress $(\mathrm{HS}+\mathrm{P})$; and Zinc-enriched probiotics plus heat stress $(\mathrm{HS}+\mathrm{ZnP})$. The experimental groups $(\mathrm{HS}+\mathrm{P}$ and $\mathrm{HS}+\mathrm{ZnP})$ were exposed to higher environmental temperature (40$42^{\circ} \mathrm{C}$ ) while the rats in the control group were raised at room temperature $\left(25^{\circ} \mathrm{C}\right)$. The experiment proceeded to 42 days, blood and liver tissues were gathered and investigated at end of the experiment to study liver morphology and indicators. The results obtained from the experiment showed, that the body weight of HS group dropped suddenly. However, elevation in liver weight and liver index was observed. H\&E examination revealed that in HS group liver sinusoids were dilated and central veins were congested. Additionally, liver histomorphology of $\mathrm{HS}+\mathrm{P}$ and $\mathrm{HS}+\mathrm{ZnP}$ was diverted to its originality and significant decrement was observed in terms of serum ALT, AST, ALP, and hepatic MDA but increment in liver SOD and GSH-PX activities was 
recorded compared to HS group. To conclude, Wistar rats can be protected from hepatic injury caused by thermal stress through $\mathrm{ZnP}$ supplementation in the diet.

Keywords: Heat stress; Inflammation; Oxidative stress; Wistar rats; Zn-Enriched probiotics

\section{Introduction}

Of the numerous bewildering and destructive stress factors, one that impinges the growth rate, feed intake, survival and immunity in rats, can be high environmental temperature [1]. Several authors have documented the destructive effects like irregular cell membrane, liver inflammation, necrosis, dilated sinusoids and hepatic venules of heat stress in rats [2]. It leads to the production of intracellular reactive oxygen species (ROS) that induces destruction to the tissues [3]. The cytokines production via activation of the $\mathrm{NF}-\kappa \mathrm{B}$ pathway is stimulated by ROS which modulates the expression of genes responsible for inflammation, stress and apoptosis. The supplementation of antioxidants are able to decrease the hurtful influences caused by thermal stress $[4,5]$.

Zinc is a significant trace element needed to the standard growing and well-being of human beings and creatures as well as impunity, growing, reproductive properties, and disease resistance have been improved with Zinc supplementation [6, 7]. Furthermore, Zinc keeps cellules from the detrimental influences of ROS generated throughout immunoactivities with the aid of antioxidants [8]. In addition to that, Zinc is an element of SOD enzyme that keeps cells from oxidative stress through catalysis of the decomposition of superoxide ions and is recognized to be triggered afterward $\mathrm{Zn}$ usage [9]. Zn standardizes genes expression such as metallothioneins (MTs) and glutathione peroxidase which are responsible for anti-oxidant procedures and its plays a vital role in $\mathrm{Cu} / \mathrm{Zn}$ SOD which regulates the expression of the genes as well as the concentration of physiological and cellular $\mathrm{Zn}^{2+}$ is significantly by MTs, $\mathrm{Zn}^{2+}$ distributors (ZnTs), that plays a crucial pattern in the imbibition, transmission, and
$\mathrm{Zn}$ excretion $[10,11]$. In like manner, the excess amount of zinc is toxic. Recently, the proper processing of $\mathrm{Zn}$ has been resulted in some good properties such as decreased poisonousness, increased imbibition and bioaccessibility, as well as lower ecological pollution, which has received more consideration [12].

Probiotics are also documented as potentially beneficial dietary supplement for the treatment of liver disorders caused by alcoholism, metabolic disorders, and viral infections [13-15]. Likewise, probiotics like Saccharomyces cerevisiae and Lactobacillus spp are able to assist in decreases of liver damage induced by oxidative stress [16]. Nowadays, a new $\mathrm{ZnP}$ product by addition of Zinc oxide into the cultivation media in what L. acidophilus and S. cerevisiahas have been grown and the feed have been developed by the College of Metabolic and Nutrition Disorders of Home Animals. The strains have the capability of production of organic zinc oxide from inorganic zinc oxide [1].

The liver is an important organ of the body has the responsibility of $\mathrm{Zn}$ metabolism and as well as for the normal liver functions [17]. Hence, some studies have been revealed that the liver of mice and rats might be protected from oxidative stress caused by diabetes or ethanol through $\mathrm{Zn}$ supplementation [18, 19]. However, it is not obvious whether liver cells can be protected in heat-stressed animals through antioxidant status, serum enzymes, and related gene expression by $\mathrm{Zn}$ supplementation. Therefore, this experiment aimed to investigate the influences of $\mathrm{Zn}$ Enriched probiotics on the antioxidant status of the liver in heat-stressed rats.

\section{Materials and Methods} Animals and research design

48, 10-week old male Wistar rodents, weighing around $200 \pm 20 \mathrm{~g}$ were gotten from 
the China, Yangzhou University of Animal Experimental Center and housed under ordinary state of $21 \pm 2{ }^{\circ} \mathrm{C}$ and $60-70 \%$ stickiness, $12 \mathrm{~h}$ light/dull cycle [20], in Nanjing Agricultural University standard lab. All Wistar rodents were given free admittance to water and food during the trial time frame. After acclimatization for multiweek, they were isolated into 4 groups (12 rodents in each group), with 3 repeats; Control group $(n=12)$; Heat stress group (HS, $\mathrm{n}=12)$; heat stress + probiotics group $(\mathrm{HS}+\mathrm{P}$, $\mathrm{n}=12)$; and heat stress $+Z \mathrm{Zn}$-enriched probiotics group $(\mathrm{HS}+\mathrm{ZnP}, \mathrm{n}=12)$. Trial method was endorsed by Nanjing Agricultural University Animal Protection and Utilization Committee (Certification No.: SYXK (Su) 2011-0036) as well as fundamental components of basal eating regimen of Wister rodents were planned consenting to the important necessities of the National Research Council [21], and are portrayed in subtleties in our previous examination [1].

\section{Test collection and preparation}

The liver is eliminated, the parallel or vertical part is derived and constant with $10 \%$ formalin then remained hepatic mass is eluted with cool saline just as kept at $-75^{\circ} \mathrm{C}$ for extra investigational work. Passing rate was $0 \%$ all through the examination. The rodents, which feed on an essential eating regimen consistently, were changed to give new water all through the preliminary. The weighing of the rodent was determined at the beginning and finishing of the analysis. Last live body weight, hepatic weight as well as hepatic index (\%) are estimated for independently Wistar rodents and at the beginning of the exploration, the ecological temperature for test rodents was $36-39-42^{\circ} \mathrm{C}$, however for control bunch was $25{ }^{\circ} \mathrm{C}$, and relative mugginess was $60-70 \%$.

\section{Planning of diet}

Probiotics (P) and Zn-enriched probiotics (ZnP) were gathered of L. acidophilus $\left(10^{11}\right.$
$\mathrm{CFU} / \mathrm{mL})$ and $\mathrm{S}$. cerevisiae $\left(10^{9} \mathrm{CFU} / \mathrm{mL}\right)$. Furthermore, the arrangement strategy was affirmed to the technique determined by [22], and the complete $\mathrm{Zn}$ content in $\mathrm{ZnP}$ was 100 $\mathrm{mg} / \mathrm{L}[20,22]$, and a Zinc containing probiotics aging medium is coordinated to change over inorganic structure into a natural structure. At long last, $1 \mathrm{~mL}$ for every day the probiotic (P) and Zn-enriched probiotics $(\mathrm{ZnP})$ eats fewer carbs were taken care of to each rodent through a gastric cylinder for 42 days. Span of the investigations was a month and a half (July 1 to August 12).

\section{Liver indicators}

The liver marker enzymes such as alanine aminotransferase or glutamic pyruvic transaminase (ALT/GPT), aspartate aminotransferase or glutamic-oxaloacetic transaminase (AST/GOT), and alanine phosphatase (ALP) level were analyzed in serum by business units consenting to the producer's directions (Wuhan Biotechnology Service Co., Ltd. China).

\section{Hepatic antioxidants}

$500 \mathrm{mg}$ cold stable hepatic sample was normalized at five $\mathrm{mL}$ cold buffer and centrifuged at $12500 \mathrm{rpm}$ for 30 seconds and then centrifuged at $3000 \mathrm{rpm}$ for 10 minutes at $4{ }^{\circ} \mathrm{C}$. The action of cancer prevention agent compounds, for example, MDA, SOD, and GSH-Px were specified from the supernatant part of the hepatic tissues utilizing business units as indicated by the producer's directions (Wuhan Biotechnology Service Co., Ltd. Wuhan, China).

\section{Histopathology}

$10 \%$ formalin were utilized for obsession of liver examples and afterward parched with not at all like level of liquor, at that point washed by xylene and utilized paraffin for installed. At last, scratch $4 \mu \mathrm{m}$ area thickness, and colored to $\mathrm{HE}$ staining. Histological contrasts, for example, dilation in the hepatocytes sinusoids and congestion of central vein were recognized underneath optical magnifying lens (Tokyo, Japan). 


\section{Statistical analysis}

The SPSS 19.0 was used for the statistical analysis of collected data. One-way ANOVA was used for the determination of significant difference among groups followed by Duncan's multiple comparison test. The Pvalue was set at 0.05 for various factors and the results were reported as mean \pm Standard Error of Mean (SEM).

\section{Results}

Probiotics and Zinc-Enriched Probiotics can improve growth performance and liver index (\%)

The differences in growth performance and liver index (\%) amongst different groups were shown in (Table 1). Before the experiment, original body weightiness of all rats was at the equal level. However, after treatment the last live body weightiness of rodents inflated heat stress (HS) was much reduce compared to control rats ( $\mathrm{p}<0.05$ ), and a slight decrease was observed as compared with probiotics and zinc-rich probiotics groups. In addition, the liver weight of the Heat stressed rats (HS) was substantially $(\mathrm{p}<0.05)$ greater as compared to control rats, while increases in $\mathrm{HS}+\mathrm{P}$ and $\mathrm{HS}+\mathrm{ZnP}$ groups were in the control range $(\mathrm{p}$ $>0.05$ ). Furthermore, liver index (\%) of the HS group was greater compared to control group ( $\mathrm{p}<0.05$ ), but it was slightly increased in the $\mathrm{HS}+\mathrm{P}$ and $\mathrm{HS}+\mathrm{ZnP}$ groups than that of the control group. Finally, the data revealed that there was no substantial variance among $\mathrm{HS}+\mathrm{P}, \mathrm{HS}+\mathrm{ZnP}$ and the control group.

Table 1. Impacts of Probiotics and Zinc-Enriched Probiotics on body weight, liver weight, and liver index of Wistar rat

\begin{tabular}{|c|c|c|c|c|}
\hline & Con & HS & HS+P & HS+ZnP \\
\hline Initial BW (g) & $230 \pm 4.1^{* \mathrm{a}}$ & $228 \pm 3.28^{\mathrm{a}}$ & $229 \pm 3.21^{\mathrm{a}}$ & $231 \pm 2^{\mathrm{a}}$ \\
\hline Final BW (g) & $322 \pm 4.18^{\mathrm{a}}$ & $220 \pm 6.56^{\mathrm{b}}$ & $285 \pm 6.98^{\mathrm{a}}$ & $310 \pm 6.35^{\mathrm{a}}$ \\
\hline Liver weight (g) & $7.6 \pm 0.7^{\mathrm{b}}$ & $10.95 \pm 0.31^{\mathrm{a}}$ & $8.12 \pm 0.16^{\mathrm{b}}$ & $8.62 \pm 0.31^{\mathrm{b}}$ \\
\hline Liver index (\%) & $2.3 \pm 0.1^{\mathrm{b}}$ & $4.9 \pm 0.8^{\mathrm{a}}$ & $2.8 \pm 0.21^{\mathrm{b}}$ & $2.7 \pm 0.32^{\mathrm{b}}$ \\
\hline
\end{tabular}

*The data is displayed as mean \pm SEM $(n=12)$, ${ }^{\text {a-b }}$ Means in the same row followed by different lowercase superscripts are significantly different $(\mathrm{p}<0.05)$

\section{Impact of Zinc-Enriched Probiotics on the Activity of Liver Marker Enzymes in Wistar rats}

The liver marker enzymes activity (e.g. ALP, AST, and ALT) are determined at serum of Wistar rats and indicated in (Table 2). The ALP, AST and ALT level of the HS group was greater $(\mathrm{p}<0.05)$ as compared to the control group. However, the serum enzyme level of the $\mathrm{HS}+\mathrm{P}$ and $\mathrm{HS}+\mathrm{ZnP}$ groups was significantly lower $(\mathrm{p}<0.05)$ as compared to the HS alone group. It is worth noting that better serum enzyme activity results were observed in the $\mathrm{HS}+\mathrm{ZnP}$ group, which proves the beneficial effects of zinc-enriched probiotic treatment. Finally, there were no substantial variance among the control and the $\mathrm{HS}+\mathrm{ZnP}$ group.

Table 2. Impacts of Probiotics and Zinc-Enriched Probiotics on AST/GOT (U/L), ALP (U/L) and ALT/GPT (U/L) and of Wistar rat

\begin{tabular}{|c|c|c|c|c|}
\hline Liver Marker Enzymes & Con & HS & HS+P & HS+ZnP \\
\hline AST(U/L) & $95 \pm 12.50^{* \mathrm{c}}$ & $290.5 \pm 18.41^{\mathrm{a}}$ & $175.6 \pm 12.17^{\mathrm{b}}$ & $115.37 \pm 19.18^{\mathrm{c}}$ \\
\hline ALP(U/L) & $300 \pm 20.03^{\mathrm{c}}$ & $800.55 \pm 28.46^{\mathrm{a}}$ & $450.12 \pm 25.08^{\mathrm{b}}$ & $320.12 \pm 25.18^{\mathrm{c}}$ \\
\hline ALT(U/L) & $60.44 \pm 9.12^{\mathrm{c}}$ & $190.6 \pm 12.19^{\mathrm{a}}$ & $121.33 \pm 9.81^{\mathrm{b}}$ & $82.7 \pm 8.84^{\mathrm{c}}$ \\
\hline
\end{tabular}

* The data is displayed as mean \pm SEM $(n=12)$. ${ }^{a-c}$ Means in the same row followed by different lowercase superscripts are significantly different $(\mathrm{p}<0.05)$ 
Impact of zinc-enriched probiotics on antioxidant enzymes in the liver of wistar rats

The (Fig. 1) shows the results of GSH-Px activity, SOD activity, and MDA content in the hepatic tissue of Wistar rats. After treatment, compared to control group, the GSH-Px and SOD activity of the HS group was substantial declined $(\mathrm{p}<0.05)$, although MDA content was substantially higher ( $\mathrm{p}<$ 0.05). Moreover, probiotics and zinc- enriched probiotics treatment considerably ( $\mathrm{p}$ $<0.05)$ increased the activity of GSH-Px and SOD, they considerably $(\mathrm{p}<0.05)$ reduced the content of MDA in the hepatic tissue of Wistar rats. Besides, there was no substantial variance in the hepatic antioxidant activity among $\mathrm{HS}+\mathrm{ZnP}$ and control group. In addition, the better results of the antioxidant activity were observed in the $\mathrm{HS}+\mathrm{ZnP}$ group.
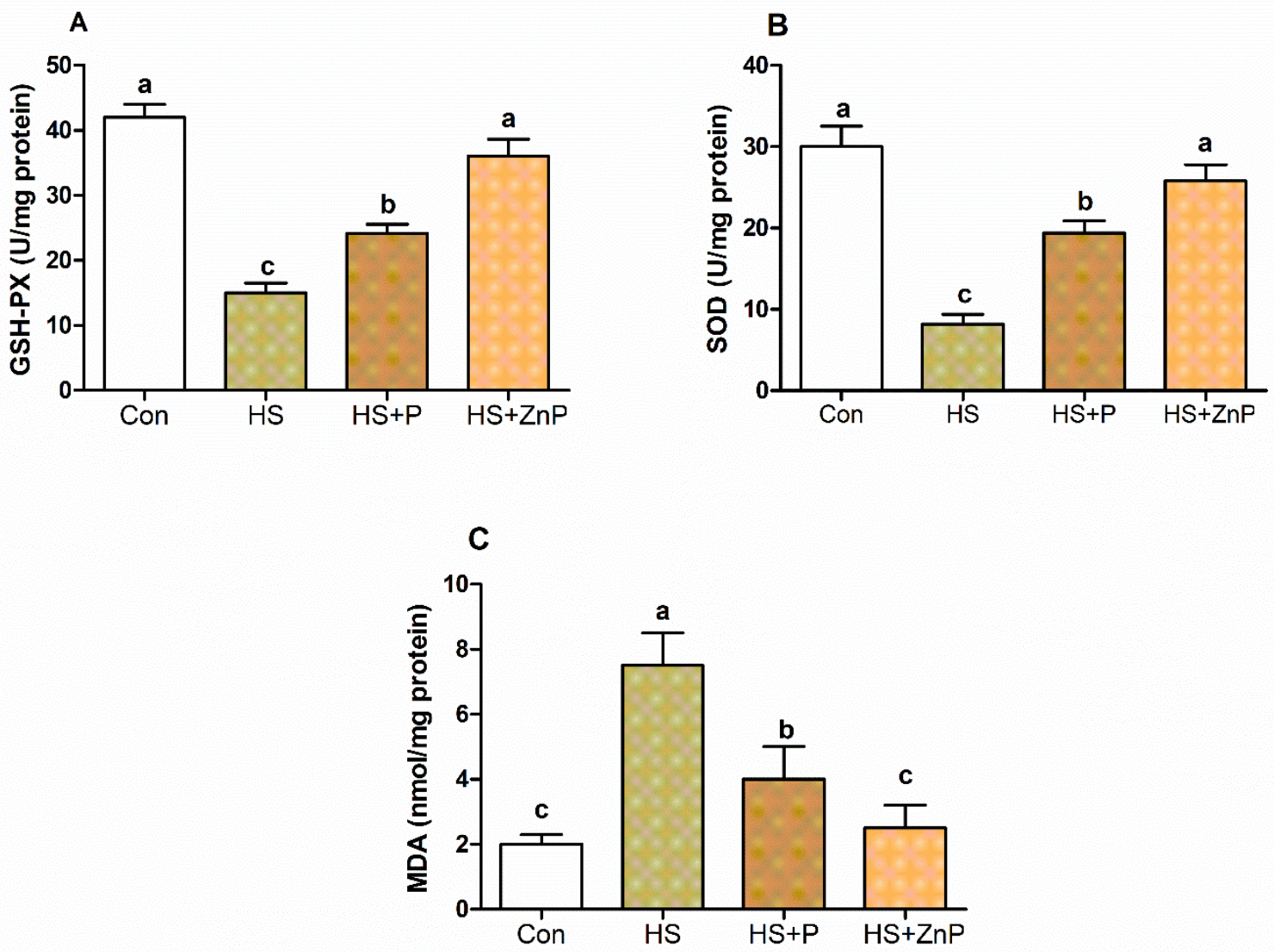

Figure 1. illustrates the influence of heat stress, probiotics, and $\mathrm{Zn}$-Enriched probiotics supplements on hepatic antioxidants. Mean of the groups are displays by bar graphs $(n=8)$, and error bars describes the standard error. $A, B$, and $C$ show the GSH-Px activity, SOD activity, and MDA content respectively. ${ }^{\text {a-c }}$ different lowercase letters on graphs display significant difference $(p<0.05)$. GSH-Px, and SOD activity, and MDA content were significantly different between control and treatment groups 
Histomorphology examination of ameliorative effect of zinc-enriched probiotics on liver injury in wistar rats induced by heat stress

The (Fig. 2) shows the results of H\&E in the hepatic tissue of exponential animals. After H\&E, the liver part of the control rats revealed ordinary liver lobule construction and portal vena. Liver cells possess an ample bright-pink cytoplasm and round nuclei. It has been detected that the enlargement of the hepatic sinusoidal curve and interstitial bleeding are the key alterations in the liver of thermal stressed rats. On the other hand, probiotic supplementation to heat stressed rats exhibited central venous congestion in the liver. Besides, heat stressed induced alteration was seen to be mostly alleviated by $\mathrm{ZnP}$ supplementation. This regulation causes the liver to display a normal, decongested portal vein enclosed by normal liver lobules.

\section{Control group}

High Temperature group

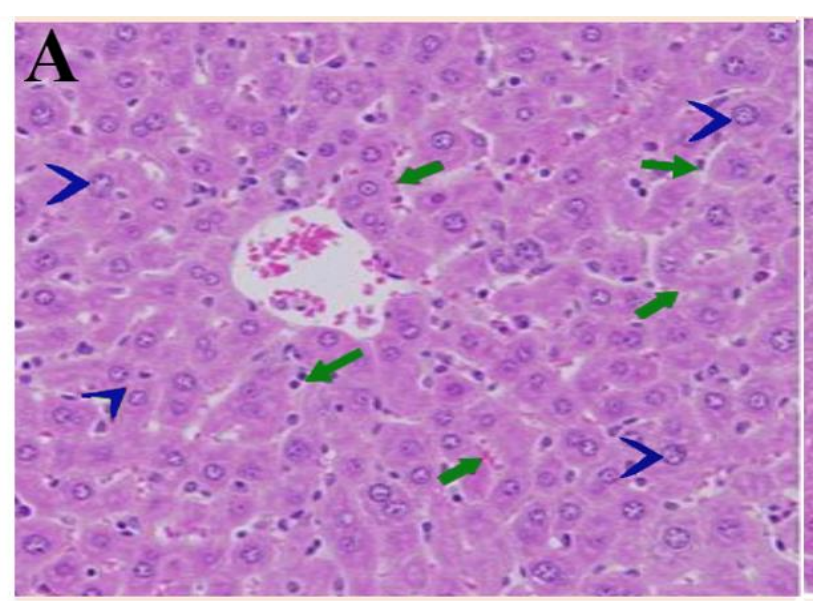

Probiotics group

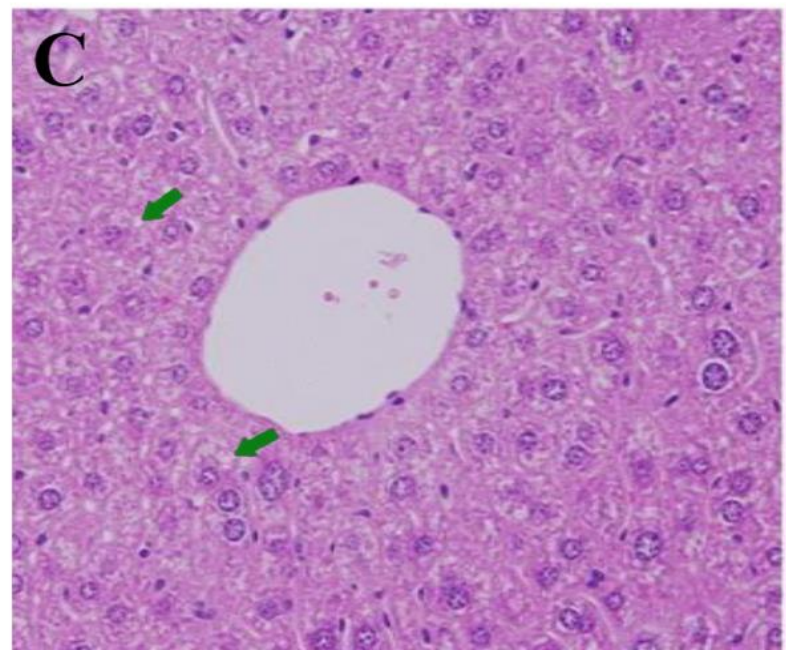

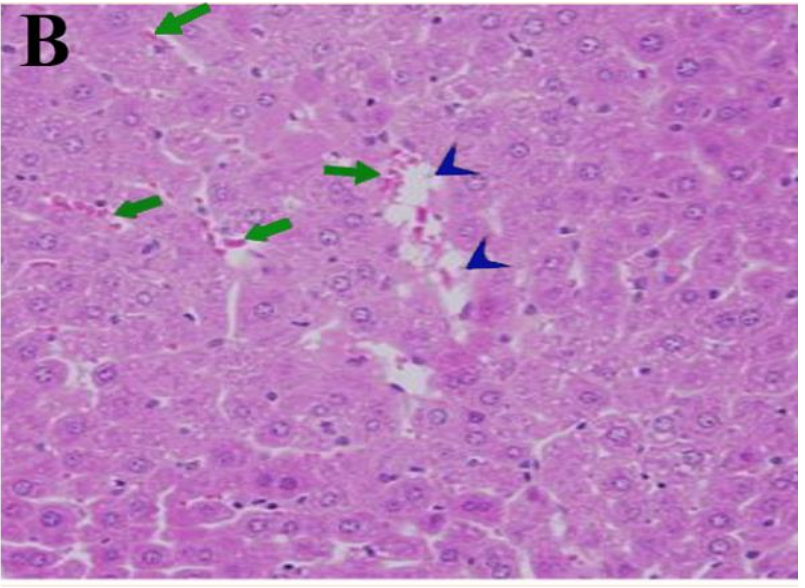

Zn-Enriched Probiotics group

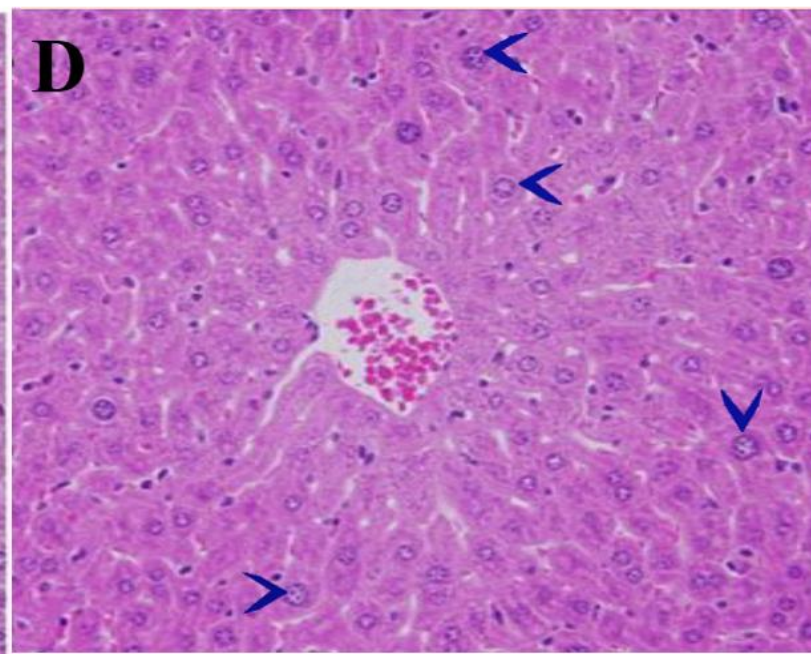

Figure 2. shows the liver sections stained with H\&E. A, B, C, and D shows the liver sections of control, $\mathrm{HS}, \mathrm{HS}+\mathrm{P}$, and $\mathrm{HS}+\mathrm{ZnP}$ groups respectively. $\mathrm{H} \& \mathrm{E}$ results revealed that high ambient temperature triggered different alterations in liver histological structure of Wistar rats, which are returned back to its originality by probiotics and Zinc-Enriched probiotics supplementation 


\section{Discussion}

The research shows that Zinc-Enriched probiotics $(\mathrm{ZnP})$ supplement are capable to decline the hepatic oxidative injury of Wistar rats reared below thermal stress because $\mathrm{ZnP}$ has antioxidant, anti-inflammatory and antiapoptosis properties.

In the month of summer, animals repeatedly suffer from thermal stress [23]. The aforementioned studies in pigs and laying hens have been revealed that thermal stress can decline growing performance, feed consumption and weight gain when raised under thermal stress $[24,25]$, but in broilers, due to reduce of feed intake the heat stress can substantially decreased liver weight [26, 27]. In mice, heat exposure have been reduce liver weight through suffering of hepatocytes physiology and a heat-sensitive organ [28, 29]. This study has shown a substantial reduction in the final body weight gain, but a significant increase in hepatic weight, and hepatic catalogue $(\%)$ recommends that the physiological functions of the liver changes due to high temperature. In addition, many researcher reported that $\mathrm{Zn}$ supplementation can capable to improve the growth performance of pigs [30, 31], as well as promote feed proficiency and increase egg in quail treated under thermal stress [32]. But, the present study indicated that $\mathrm{ZnP}$ has not affect the body and liver weights of Wistar rats inflated under thermal stress. Moreover, the results of this study are constant with earlier testified results that $\mathrm{Zn}$ supplementation has not increase the liver weights of mice inflated under thermal stress [33].

AST, AKP, and ALT are normally used as liver indicators [34]. Earlier researchers have revealed that under thermal stress, the TP concentration in serum are substantially decrease as well as AST and ALT concentration are substantially increased paralleled to negative control [2]. In our results, we investigated that the liver has seriously affected by HS group and exhibited liver injury, as well as the activity of liver biomarkers such as AST and ALT are significantly increased, and these results well consistent with previous reports. Likewise, histological examination of liver tissue in the HS group was severely damaged, liver cells were irregularly arranged and nuclear damage was caused. Oral Zinc therapy has been reported to reduce serum AST activity in rats [35]. This study shows that dietary $\mathrm{ZnP}$ supplements can not only improve the increase of AST activity, but also relieve liver tissue damage caused by heat. Interestingly, the AST activity of the HS + $\mathrm{ZnP}$ group was decreased as paralleled to the control group [35].

The ROS or free radicals generation and increases of lipid peroxidation are involves in cellular oxidative stress that induced by heat stress $[36,37]$, also free radicals induce by MDA, which is the final products of the lipid peroxidation. Therefore, MDA content are often referred to as oxidative stress markers [38]. Furthermore, thermal stress exposure increases MDA concentration, reduces GSH and GSH-PX activity in liver, heart and kidney tissue of Wistar rats as well as antioxidant enzymes such as GSH and GSHPX designated severe oxidative damage [1]. In our study, increased MDA concentrations and lower levels of the antioxidant enzyme, SOD, and GSH-PX led to oxidative damage to the liver in the HS group. We investigated that $\mathrm{ZnP}$ may be involved in several components of oxidant defense, including SOD, which is an important part of the antioxidant system. In addition, Celino et al. reported that high levels of $\mathrm{Zn}$ increased the enzyme activity of CuZn-SOD, thereby reducing the production of ROS in the testes of eels [39]. Consistent with these, our findings suggest that additional $\mathrm{ZnP}$ increases SOD and GSH-PX activity and continuously reduces MDA concentrations in the livers of heat-exposed Wistar rats, but the 
decrease in MDA concentrations may be caused by exposure to high levels of $\mathrm{ZnP}$ [1]. Therefore, $\mathrm{ZnP}$ can reduce oxidative damage by increasing antioxidant enzyme activity.

\section{Conclusion}

This study outlines $\mathrm{ZnP}$ as a potential nutritional support in Wistar rats expand at high ambient temperature. We investigated that $\mathrm{ZnP}$ is a potential nutritional supplement that prevents liver oxidation, inflammatory response and necrosis through increasing antioxidants, and protects liver by regulating the improvement of liver marker enzymes caused by heat stress. In addition, it provides a novel strategy for animal feed in tropical and subtropical areas to dominate summer stress pathogenesis in animal production.

\section{Authors' contributions}

Conceived and designed the experiments: RM Malyar \& J Tanha, rformed the experiments: $\mathrm{Z}$ Ziauddin, KS Ismail, $\mathrm{M}$ Ibrahimi \& AR Khalid, Analyzed the data: B Hanifullah, RM Malyar, J Tanha \& WA Vistro, Contributed materials/ analysis/ tools: SA Banuree, Wrote the paper: RM Malyar

\section{Acknowledgement}

The authors are grateful to the Department of Clinical Veterinary Medicine, College of Veterinary Medicine, and Nanjing Agricultural University. Nanjing 210095, China.

\section{References}

1. Malyar RM, Li H, Enayatullah H, Hou L, Farid RA, Liu D, Bhat JA, Miao J, Gan F, Huang K \& Chen X. (2019). Zincenriched probiotics enhanced growth performance, antioxidant status, immune function, gene expression, and morphological characteristics of Wistar rats raised under high ambient temperature. 3 Biotech 9(8): 291.

2. Malyar RM, Naseri E, Li H, Ali I, Farid RA, Liu D, Maroof K, Nasim M, Banuree SA, Huang K \& Waldron KJ (2020). Hepatoprotective Effects of SeleniumEnriched Probiotics Supplementation on
Heat-Stressed Wistar Rat Through AntiInflammatory and Antioxidant Effects. Biol Trace Element Res. 7:1-2.

3. Chauhan SS, Celi P, Fahri FT, Leury BJ \& Dunshea FR (2014). Dietary antioxidants at supranutritional doses modulate skeletal muscle heat shock protein and inflammatory gene expression in sheep exposed to heat stress. J Anim Sci 92(11): 4897-908.

4. Arrigo T, Leonardi S, Cuppari C, Manti S, Lanzafame A, D'Angelo G, Gitto E, Marseglia L \& Salpietro C (2015). Role of the diet as a link between oxidative stress and liver diseases. World $J$ Gastroenterol 21(2): 384-395.

5. Kamboh AA, Hang SQ, Bakhetgul M \& Zhu WY. (2013). Effects of genistein and hesperidin on biomarkers of heat stress in broilers under persistent summer stress. Poult Sci 92(9): 2411-2418.

6. Poulsen HD (1995). Zinc Oxide for Weanling Piglets. Acta Agriculturae Scandinavica, Section A - Animal Sci 45(3): 159-167.

7. Hahn JD \& Baker DH (1993). Growth and plasma zinc responses of young pigs fed pharmacologic levels of zinc. J of Ani Sci 71(11): 3020-3024.

8. King LE, Osati-Ashtiani F \& Fraker PJ (1995). Depletion of cells of the B lineage in the bone marrow of zinc-deficient mice. Immunol 85(1): 69-73.

9. Buzadžić B, Korać B, Lazić T, \& Obradović D (2002). Effect of supplementation with $\mathrm{Cu}$ and $\mathrm{Zn}$ on antioxidant enzyme activity in the rat tissues. Food Res Inter 35(2-3): 217-220.

10. Dong G, Chen H, Qi M, Dou Y \& Wang Q (2014). Balance between metallothionein and metal response element binding transcription factor 1 is mediated by zinc ions. Mol Medic Rep Vol 11.

11. Kambe T, Tsuji T, Hashimoto A \& Itsumura N (2015). The Physiological, 
Biochemical, and Molecular Roles of Zinc Transporters in Zinc Homeostasis and Metabolism. Physiol Rev 95(3): 749784.

12. Carlson MS, Boren CA, Wu C, Huntington CE, Bollinger DW \& Veum TL (2004). Evaluation of various inclusion rates of organic zinc either as polysaccharide or proteinate complex on the growth performance, plasma, and excretion of nursery pigs. J Anim Sci 82(5): 1359-1366.

13. Loguercio C, Federico A, Tuccillo C, Terracciano F \& D'Auria MV, De Simone C \& Blanco CD (2005). Beneficial effects of a probiotic VSL\#3 on parameters of liver dysfunction in chronic liver diseases. J Clin Gastroenterol 39(6): 540-543.

14. Cesaro C, Tiso A, Del Prete A, Cariello R, Tuccillo C, Cotticelli G, del Vecchio Blanco C \& Loguercio C (2011). Gut microbiota and probiotics in chronic liver diseases. Digestive and Liver Dise 43(6): 431-438.

15. Wang Y, Kirpich I, Liu Y, Ma Z, Barve S, McClain CJ \& Feng W (2011). Lactobacillus rhamnosus GG treatment potentiates intestinal hypoxia-inducible factor, promotes intestinal integrity and ameliorates alcohol-induced liver injury. Am J Pathol 179(6): 2866-2875.

16. Liu Y, Liu Q, Ye G, Khan A, Liu J, Gan F, Zhang $X$, Kumbhar S \& Huang K (2015). Protective effects of Seleniumenriched probiotics on carbon tetrachloride-induced liver fibrosis in rats. J Agric Food Chem 63(1): 242-249.

17. Stamoulis I, Kouraklis $\mathrm{G} \&$ Theocharis $S$ (2007). Zinc and the Liver: An Active Interaction. Dig Diseas and Sci 52(7): 1595-1612.

18. Wang X, Li H, Fan Z \& Liu Y (2012). Effect of zinc supplementation on type 2 diabetes parameters and liver metallothionein expressions in Wistar rats. J Physiol Biochem 68(4): 563-572.

19. Zhou Z, Wang L, Song Z, Saari JT, McClain CJ \& Kang YJ (2005). Zinc supplementation prevents alcoholic liver injury in mice through attenuation of oxidative stress. Am J Pathol 166(6): 1681-1690.

20. Malyar RM, Li H, Enayatullah H, Hou L, Farid RA, Liu D, Bhat JA, Miao J, Gan F, Huang K \& Chen X (2019). Zincenriched probiotics enhanced growth performance, antioxidant status, immune function, gene expression, and morphological characteristics of Wistar rats raised under high ambient temperature. 3 Biotech 9(8): 291.

21. Council, NR (1995). Nutrient Requirements of Laboratory Animals,: Fourth Revised Edition. Washington, DC: The National Academies Press 192.

22. Gan F, Ren F, Chen X, Lv C, Pan C, Ye G, Shi J, Shi X, Zhou H, Shituleni SA \& Huang K (2013). Effects of seleniumenriched probiotics on heat shock protein mRNA levels in piglet under heat stress conditions. J Agri and Food Chem 61(10): 2385-2391.

23. Bhusari S, Hearne LB, Spiers DE, Lamberson WR \& Antoniou E (2008). Transcriptional profiling of mouse liver in response to chronic heat stress. $J$ Therm Biol 33(3): 157-167.

24. Spencer JD, Boyd RD, Cabrera R \& Allee GL (2003). Early weaning to reduce tissue mobilization in lactating sows and milk supplementation to enhance pig weaning weight during extreme heat stress 1,2. J Anim Sci, 81(8): 2041-2052.

25. Song Z, Liu L, Sheikhahmadi A, Jiao H \& Lin H (2012). Effect of Heat Exposure on Gene Expression of Feed Intake Regulatory Peptides in Laying Hens. $J$ Biomed \& Biotech pp. 484869.

26. Geraert PA, Padilha JC \& Guillaumin S (1996). Metabolic and endocrine changes 
induced by chronic heat exposure in broiler chickens: growth performance, body composition and energy retention. Br J Nutr 75(2): 195-204.

27. Bartlett JR, \& Smith MO (2003). Effects of different levels of zinc on the performance and immunocompetence of broilers under heat stress. Poult Sci 82(10): 1580-1588.

28. Bhusari S, Hearne LB, Spiers DE, Lamberson WR \& Antoniou E (2008). Transcriptional profiling of mouse liver in response to chronic heat stress. $J$ Therm Biol 33(3): 157-167.

29. Hall DM, Xu L, Drake VJ, Oberley LW, Oberley TD, Moseley PL \& Kregel KC (2000). Aging reduces adaptive capacity and stress protein expression in the liver after heat stress. J Appl Physio 89(2): 749-759.

30. Case CL \& Carlson MS (2002). Effect of feeding organic and inorganic sources of additional zinc on growth performance and zinc balance in nursery pigs. $J$ Anim Sci 80(7): 1917-1924.

31. Hu C, Song J, You Z, Luan Z \& Li W (2012). Zinc oxide-montmorillonite hybrid influences diarrhea, intestinal mucosal integrity, and digestive enzyme activity in weaned pigs. Biol Trace Elem Res 149(2): 190-196.

32. Sahin K \& Kucuk O (2003). Zinc supplementation alleviates heat stress in laying Japanese quail. J Nutr 133(9): 2808-2811.

33. Wang F, Li Y, Cao Y \& Li C (2015). Zinc might prevent heat-induced hepatic injury by activating the Nrf2-antioxidant in mice. Biol Trace Elem Res 165(1): 8695.

34. Goorden SM, Buffart TE, Bakker A \& Buijs MM (2013). [Liver disorders in adults: ALT and AST]. Ned Tijdschr Geneeskd 157(43): A6443.

35. Santon A, Irato P, Medici V, D'Incà R, Albergoni V \& Sturniolo GC (2003). Effect and possible role of $\mathrm{Zn}$ treatment in LEC rats, an animal model of Wilson's disease. Biochim Biophys Acta 1637(1): 91-97.

36. Kikusato M \& Toyomizu M (2013). Crucial role of membrane potential in heat stress-induced overproduction of reactive oxygen species in avian skeletal muscle mitochondria. PLoS One 8(5): e64412.

37. Kim KJ, Yoon KY, Hong HD \& Lee BY (2012). Schisandra chinensis prevents hepatic lipid peroxidation and oxidative stress in rats subjected to heat environmental stress. Phytother Res 26(11): 1674-1680.

38. Gaweł S, Wardas M, Niedworok E \& Wardas P (2004). Malondialdehyde (MDA) as a lipid peroxidation marker. Wiad Lek 57(9-10): 453-455.

39. Celino FT, Yamaguchi S, Miura C, Ohta T, Tozawa Y, Iwai T \& Miura T (2011). Tolerance of Spermatogonia to Oxidative Stress Is Due to High Levels of $\mathrm{Zn}$ and $\mathrm{Cu} / \mathrm{Zn}$ Superoxide Dismutase. PLOS ONE 6(2): e16938. 